\title{
A social work study on family related issues influencing juvenile delinquency
}

\author{
Mohammad Reza Iravani $^{\mathrm{a}^{*}}$, Samaneh Salimi ${ }^{\mathrm{b}}$, Akram Fakhri Fakhramini ${ }^{\mathrm{c}}$, Ghasem Shahmoradi ${ }^{\mathrm{d}}$, \\ Zakaria Eskandari ${ }^{\mathrm{e}}$ and Mohsen Dadashi ${ }^{\mathrm{f}}$
}

\begin{tabular}{l}
\hline A R T I C L E I N F O \\
\hline Article history: \\
Received January 20, 2013 \\
Received in Revised form \\
March, 11, 2013 \\
Accepted 7 June 2013 \\
Available online \\
8 June 2013 \\
\hline Keywords: \\
Juvenile delinquency \\
Religion and juvenile delinquency \\
Economy and Juvenile \\
delinquency
\end{tabular}

${ }^{a}$ Assistant Professor, Department of Social Work, Islamic Azad University Khomeinishahr Branch, Daneshjou Blvd, Iran

${ }^{b}$ Counseling Department, University of Esfahan, Esfahan, Iran

${ }^{c}$ MA Student, Department of Sociology, Dehaghan Branch, Islamic Azad University, Isfahan, Iran

${ }^{d}$ MSc in Clinical Psychology, Faculty of Education and Psychology, Tabriz University, Tabriz, Iran.

${ }^{e}$ MSc in clinical psychology,Shahid Beheshti University of Medical Sciences, Tehran, Iran

${ }^{f}$ Phd Student in Clinical psychology, Tehran University of Medical Sciences,(on a scholarship faculty Zanjan university of medical sciences), Iran

\begin{abstract}
We present a study to investigate the impacts of various factors on juvenile delinquency. The study distributes 400 questionnaires among young people aged 19-26 who are involved with some sort of crime and analyzes their feedbacks. There are three hypotheses including family income, tendency to spirituality and religion and educational backgrounds of families and juvenile delinquency among these people. The results show that while family income and religious as well as spirituality characteristics play important role on juvenile delinquency, educational background of the parents do not statistically have any influence on juvenile delinquency. The study recommends that a better family condition could contribute society to reduce juvenile delinquency and people could guide their children through better consultations.
\end{abstract}

\section{Introduction}

Juvenile delinquency is one of the most important issues in any society and there are tremendous efforts to reduce crimes and violence among young people who are supposed to be responsible for future development of country. For years, there have been enormous attempts for studying the motives behind the juvenile delinquency. Swift (1909), for instance, discussed juvenile delinquency and juvenile control. Durea (1933) presented a study on attitudes toward juvenile delinquency and reported murder as the most critical offense and truancy as the least serious. Peterson et al. (1959) studied personality and background factors in juvenile delinquency. Quay et al. (1960) presented three personality factors in juvenile delinquency. Kósa et al. (1993) investigated juvenile delinquency and drug dependence in Hungary. Ryan \& Testa (2005) performed a comprehensive study on child

\footnotetext{
* Corresponding author. Tel: + 989130758065

E-mail addresses: iravani@iaukhsh.ac.ir (M. R. Iravani) 
maltreatment and juvenile delinquency by studying the effect of placement and placement instability. They stated that substantiated victims of maltreatment average $47 \%$ higher delinquency rates than children not indicated for abuse or neglect while $16 \%$ of children placed into substitute care experienced at least one delinquency petition. Ozen et al. (2005) investigated juvenile delinquency in Turkey and determined the effects of offence behavior, socio-demographic specifications and some issues on juvenile offenders' families in a selected region, and compared their results with developed countries. They stated that some items such as low income and low family educational levels, insufficient parental control, crowded family, migration, repetition of offences, and cigarette smoking were important risk factors for offensive behavior. van Dam et al. (2005) investigated which of the two personality models, PEN or Big Five, could differentiate best between Dutch juvenile offenders and college students, between Dutch self-reported recidivists and non-recidivists.

Chung and Steinberg (2006) studied the relationship between neighborhood factors, parenting behaviors, peer deviance, and delinquency among some juvenile offenders and explained that weak neighborhood social organization was indirectly related to delinquency through its relationship with parenting behavior and peer deviance. Ryan et al. (2008) implemented administrative data from a large urban county and propensity score matching to investigate the relationship between group home placements in child welfare and the risk of delinquency based on a sample size of 8226 people. They stated that the relative risk of delinquency was nearly two and one half times bigger for adolescents with at least one group home placement.

Ohtani et al. (2008) studied the relationship between the month of birth and juvenile delinquency and reported no substantial difference between observed and expected numbers of births in winter/summer or those in the first/last months of the sample size of investigation. Gardner et al. (2009) studied the effect of peer context among adolescent boys and girls with varied histories of problem behavior by looking into the relationship between sports participation and juvenile delinquency. They stated that the odds of nonviolent delinquency were higher among boys who took part in sports when compared with boys who took part in nonathletic activities.

Ryan et al. (2010) investigated the relationship between kinship foster care and the risk of juvenile delinquency and stated that the relative risk of delinquency was bigger for African American and white male adolescents served in kin homes. Chui \& Chan (2011) executed an empirical study on social bonds and male juvenile delinquency while on probation in Hong Kong and stated that poor parental bonding and negative belief in the legal system could increase the propensity to commit theft and violent delinquency, respectively, including the probation period. They stated that the increase level of involvement in organizational activities could yield in the increase of propensity to commit violent crime. They reported the implications for social services, which target the juvenile offenders in terms of fostering a healthy parent-child bonding.

In this paper, we study three factors influencing juvenile delinquency among young people who live in city of Esfahan, Iran by gathering information from nearly 400 people. The organization of this paper first, presents the questions of our survey in section 2 and the results are given in section 3 . Finally, concluding remarks are given in the last to summarize the contribution of the paper.

\section{The proposed study}

The study distributes 400 questionnaires among young people aged 19-26 who are involved with some sort of crime and analyzes their feedbacks. There are three hypotheses including family income, tendency to spirituality and religion and educational backgrounds of families and juvenile delinquency among these people. 


\section{The results}

\subsection{The relationship between family income and juvenile delinquency}

The first hypothesis of this survey is associated with the relationship between family income and juvenile delinquency. Table 1 summarizes details of our survey.

\section{Table 1}

The relationship between family income and juvenile delinquency

\begin{tabular}{lcccc}
\hline & \multicolumn{4}{c}{ juvenile delinquency } \\
\cline { 2 - 5 } & & High & Low & Sum \\
& No & 113 & 136 & 249 \\
Unsuitable family income & Yes & 46 & 93 & 139 \\
\cline { 2 - 5 } Sum & & 259 & 229 & 388 \\
\hline
\end{tabular}

The Chi-square was calculated as $\chi^{2}=5.569$ P-value $=0.018$ with $\mathrm{df}=1$, which means we can reject the null hypothesis and conclude that a sever family income could influence juvenile delinquency.

\subsection{The relationship between family religious as well as spirituality and juvenile delinquency}

The second hypothesis of this survey is associated with the relationship between family religious as well as spirituality and juvenile delinquency. Table 2 summarizes details of our survey.

\section{Table 2}

The relationship between religious as well as spirituality and juvenile delinquency

\begin{tabular}{llccc}
\hline & \multicolumn{4}{c}{ juvenile delinquency } \\
\cline { 2 - 5 } & & High & Low & Sum \\
& No & 53 & 168 & 221 \\
Religious as well as spirituality & Yes & 22 & 145 & 167 \\
\cline { 2 - 5 } Sum & & 75 & 313 & 388 \\
\hline
\end{tabular}

The Chi-square was calculated as $\chi^{2}=7.126 \mathrm{P}$-value $=0.008$ with $\mathrm{df}=1$, which means we can reject the null hypothesis and conclude that a low level of believes on religion as well as spirituality among families could significantly influence juvenile delinquency.

\subsection{The relationship between family's educational backgrounds and juvenile delinquency}

The third hypothesis of this survey is associated with the relationship between educational backgrounds of families and juvenile delinquency. Table 3 summarizes details of our survey.

\section{Table 3}

The relationship between family’s educational backgrounds and juvenile delinquency

\begin{tabular}{lcccc}
\hline & \multicolumn{3}{c}{ Juvenile delinquency } \\
\cline { 2 - 5 } & & High & Low & Sum \\
Family educational background & Low & 119 & 172 & 291 \\
Sum & High & 39 & 58 & 97 \\
\cline { 2 - 5 } & & 158 & 230 & 388 \\
\hline
\end{tabular}

The Chi-square was calculated as $\chi^{2}=0.014 \mathrm{P}$-value $=0.905$ with $\mathrm{df}=1$, which means we cannot reject the null hypothesis and conclude that there is no relationship between family educational background and juvenile delinquency. In summary, we have found that family income as well as religious characteristics play important role on juvenile delinquency in Iranian society. However, there were no evidences to believe that family educational background had any impact on juvenile delinquency. 


\section{Conclusion}

We have presented a study to investigate the impacts of three factors on juvenile delinquency. The study distributed 388 questionnaires among people who were involved with crime and analyzed their feedbacks. There were three hypotheses in our survey and we were looking to detect whether family income, religion and educational backgrounds play important role on juvenile delinquency in Iranian society. The results of our survey indicated that while family income and their religious backgrounds were important on juvenile delinquency, family's educational background did not statistically influence juvenile delinquency. The study suggests that a better family condition could help reduce juvenile delinquency and people could guide their children through better consultations.

\section{Acknowledgment}

The study was supported by Islamic Azad University and the author would like to thank the officials for their supports.

\section{References}

Chui, W.H., \& Chan, H.C. (2011). Social bonds and male juvenile delinquency while on probation: An exploratory test in Hong Kong. Children and Youth Services Review, 33(11), 2329-2334.

Chung, H.L., \& Steinberg, L. (2006). Relations between neighborhood factors, parenting behaviors, peer deviance, and delinquency among serious juvenile offenders. Developmental Psychology, 42(2), 319-331.

Durea, M.A. (1933). An experimental study of attitudes toward juvenile delinquency. Journal of Applied Psychology,17(5), 522-534.

Gardner, M., Roth, J., \& Brooks-Gunn, J. (2009). Sports participation and juvenile delinquency: The role of the peer context among adolescent boys and girls with varied histories of problem behavior. Developmental Psychology, 45(2), 341-353.

Kósa, F., Lászik, A., Antal, A., \& Szendrényi, J. (1993). Juvenile delinquency and drug dependence in Hungary. Forensic Science International, 62(1-2), 29-36.

Ozen, S., Ece, A., Oto, R., Tirasci, Y. \& Goren, S. (2005). Juvenile delinquency in a developing country: A province example in Turkey. International Journal of Law and Psychiatry, 28(4), 430441.

Peterson, D.R., Quay, H.C., \& Cameron, G.R. (1959). Personality and background factors in juvenile delinquency as inferred from questionnaire responses. Journal of Consulting Psychology, 23(5), 395-399.

Ohtani, T., Sasaki, T., Kadomoto, I., Kato, N., \& Yoshinaga, C. (2008). Birth months and vulnerability to juvenile delinquency. Progress in Neuro-Psychopharmacology and Biological Psychiatry, 32(1), 49-53.

Quay, H.C., Peterson, D.R., \& Consalvi, C. (1960).The interpretation of three personality factors in juvenile delinquency. Journal of Consulting Psychology, 24(6), 555.

Ryan, J.P., \& Testa, M. F. (2005). Child maltreatment and juvenile delinquency: Investigating the role of placement and placement instability. Children and Youth Services Review, 27(3), 227-249.

Ryan, J.P., Hong, J.S., Herz, D., \& Hernandez, P.M. (2010). Kinship foster care and the risk of juvenile delinquency. Children and Youth Services Review, 32(12), 1823-1830.

Ryan, J.P., Marshall, J.M., Herz, D., \& Hernandez, P.M. (2008). Juvenile delinquency in child welfare: Investigating group home effects. Children and Youth Services Review, 30(9), 1088-1099.

van Dam, C., Janssens, J.M.A.M., \& De Bruyn, E.E.J. (2005). PEN, Big Five, juvenile delinquency and criminal recidivism. Personality and Individual Differences, 39(1), 7-19.

Swift, E. J. (1909). Juvenile delinquency and juvenile control. Psychological Bulletin, 6(4), 127-129. 